\title{
Female Urinary Incontinence - A Revisit on Prevalence of this Problem in Today's Society, which is Increasing due to Increase in Average Life Span
}

\section{Jindal Preeti ${ }^{1 *}$, Gupta Madhu' ${ }^{2}$, Kundal Isha ${ }^{3}$, Muskan Mittal ${ }^{4}$, Gulati Ridhi $^{5}$, Malhi Cherry ${ }^{5}$ and Akanksha Nigam ${ }^{5}$}

${ }^{1}$ Consultant Fortis Hospital and Director, The Touch clinic - Advanced IVF and Gyne Centre, Mohali, India

${ }^{2}$ Professor, Department of Community Medicine and School of Public Health, Postgraduate Institute of Medical Education and Research (PGIMER), Chandigarh, India

${ }^{3}$ Medical Officer, The Touch Clinic, Mohali, Punjab, India

${ }^{4}$ RMO, The Touch Clinic, Mohali, Punjab, India

${ }^{5}$ Consultant, The Touch Clinic, Mohali, Punjab, India

*Corresponding Author: Jindal Preeti, Consultant Fortis Hospital and Director, The Touch clinic - Advanced IVF and Gyne Centre, Mohali, India.
Received: July 08, 2021

Published: August 12, 2021

(C) All rights are reserved by Jindal Preeti., et al.

\begin{abstract}
Objectives: As postmenopausal life span is increasing, urinary incontinence is one of the problems that has emerged as leading issues affecting quality of life of these women. Despite its prevalence this problem is often neglected and ridiculed as a condition which most women have to live with. It is important that we relook into this problem and not brush it under the carpet. This study was conducted to estimate the prevalence of urinary incontinence in women of all age groups (more than 18 years) and its impact on their quality of life which was studied so that true gravity of this problem in Indian scenario can be understood. Also now days several new non invasive methods like laser, radiofrequency, carboxytherapy, PRP, HIFEM are available with very satisfactory results and can be offered to these women [1]. Their role is also discussed in this article.

Methods: A cross-sectional study was conducted from September 2019 to February 2020 among women of age 18 years and above. The Incontinence Questionnaire-Urinary Incontinence Short Form (ICIQ-UI-SF) questionnaire was used to estimate the prevalence and WHOQOL- Age tool used to assess quality of life.

Results: The prevalence of urinary incontinence was observed to be $25.8 \%$. It was significantly ( $<<0.05$ ) higher in age group of 66 75 years (33.6\%) and 76 - 85 years (46.7\%) as compared to other groups. Nearly $14.8 \%$ women in the age group of 15 - 25 years were affected. Social quality of life was affected significantly (38.4\%) in these women though they were able to carry on daily life activity with UI ( $\mathrm{p}=0.022)$. Urinary incontinence decreased their self confidence and increased hesitancy to go to social events.

Conclusion: A significant prevalence of urinary incontinence affecting one in every fourth women with increasing age was observed. Also significant differences were observed in quality of life index parameters in those who were affected with urinary incontinence problems. Now a days several new modalities of treatment which are painless, non invasive and out patient based are available to treat urinary incontinence.
\end{abstract}

Keywords: Urinary Incontinence (UI); SUI Prevalence in North India; Quality of Life in SUI; Postmenopausal Women 


\section{Abbreviations}

UI: Urinary Incontinence; SUI: Stress Urinary Incontinence; PRP: Platelet Rich Plasma; HIFEM: High Intensity Focused Electromagnetic Field; ICIQ-UI-SF: Incontinence Questionnaire-Urinary Incontinence Short Form; WHOQOL: World Health Organization Quality of Life; ICS: International Continence Society; SWL: Satisfaction With Life; HIFU: High Intensity Focused Ultrasound

\section{Introduction}

Owing to accessible and improved medical health care, an average woman lives 20 - 40 years of her life in the postmenopausal period. Yet, many women suffer following menopause; urinary incontinence is one of them. Average women affected with urinary incontinence (UI) are $23 \%$ to $55 \%$ [1-3] (*These are facts hence reference is given and we have quoted this study). The stress urinary incontinence is leakage of urine with increase in abdominal pressure like on sneezing, coughing, laughing or playing sports. The urge incontinence is strong, uncontrollable urge to urinate, with a high chance of losing urine if a restroom is not found and mixed incontinence is when both stress and urge exist.

Urinary incontinence in women is an underrated problem as there is hesitancy in seeking help due to the lack of knowledge [3]. The fact suggests that this is a "hidden" problem, underestimated both by the sufferer and by healthcare professionals. This condition is more common in women than in men due to anatomical and physiological reasons. The shorter length of urethra in women, child bearing, post menopausal hypo estrogenic atrophic changes and recurrent urinary and vaginal infections leading to more damage locally are main contributory factors for women suffering more with this problem [4]. Urinary incontinence can significantly impair quality of life and has social, medical, physical and mental harmful effects in women.

Stress urinary incontinence (SUI) is defined by the International Continence Society (ICS) as "the complaint of any involuntary loss of urine on effort or physical exertion (e.g. sporting activities) or on sneezing or coughing" [5]. This explanation in response to your comment.

Stress incontinence leads to escape of urine through the urethra when the intraabdominal (and therefore intravesical) pressure is raised by a sudden movement, coughing, sneezing, laughing, walking or, in certain cases, even turning in bed [6].
In extreme cases it requires a rise in bladder pressure to only 20 or $30 \mathrm{~cm}$ of water to cause a leak. In mild cases the pressure may have to be raised to 70 or $80 \mathrm{~cm}$ of water. The amount of urine lost at any one time is usually only a few drops and this is a feature important in the diagnosis. The frequent and repeated small leaks lead to soreness and excoriation of the vulva necessitating frequent changes of underclothing or the constant wearing of the protective clothing. It increases incidence of local infections and also risks of injury due to fall increases as sometimes women have to run to washrooms to avoid embarrassment due to leakage. In severe cases the woman's life becomes a misery; she feels a social outcast and avoids leaving the house all together [7].

The association between aging and urge incontinence is relatively easily explained: ultra structural changes in the bladder and distinct changes in receptor response provide a partial explanation for the rising prevalence of urge incontinence with increasing age [8].

The primary objective of this study is to estimate the prevalence of urinary incontinence along with the domains of quality of life in women affected with urinary incontinence. The prevalence of UI is related to various factors such as advanced age of the woman, parity, mode of delivery, obesity and others. Age plays an important factor in etiology. Thus with increase in mean life expectancy, the overall prevalence of UI in women is expected to increase in the future.

\section{Methodology}

Study area and study design

A cross -sectional study was conducted for estimating the prevalence of urinary incontinence, its correlates and associated factors in North India.

\section{Study population}

All women aged more than 18 years were eligible to participate in the study. Inclusion criteria were - women above 18 years of age, who consented to be the part of the study. Exclusion criteria were pregnant women, active urinary tract or vaginal infection, active vaginal bleeding due to any cause, medical comorbidities such as diabetes, history of an accident or pelvic injury, any disease like neurological and congenital that could cause urinary incontinence or who were unlikely to complete the study protocol treatment for logistic reasons. 
Female Urinary Incontinence - A Revisit on Prevalence of this Problem in Today's Society, which is Increasing due to Increase in Average Life Span

Sample size

Sample size was calculated using the formula $\mathrm{n}=4(\mathrm{pq} / \mathrm{l} 2)$, where $n$ is the sample size, $p$ is prevalence, $q$ is $p-1$, and $l$ is precision. Assuming the average prevalence of urinary continence of $27 \%$ in community-based studies [9], and $l$ as $5 \%$, the sample size comes out to be 316 . Considering non-response rate or refusal rate as $20 \%$, the total sample size came out to be 380 . To take care of the clustering, design effect of 2 was applied. So, the total sample size was estimated to be 760 . We studied total of 1018 women to get more accurate results.

\section{Sampling technique}

Those women who attended Obstetrics and Gynaecology private clinic in Mohali (The Touch Clinic) with chief complaints other than incontinence in time period from $7^{\text {th }}$ September 2019 to $29^{\text {th }}$ February 2020 were eligible to participate in the study. Self filled questionnaire were given to all participating women. In addition, women visiting public places like malls, cinemas, exhibitions were randomly approached and requested to participate in the study.

\section{Study instruments}

International consultation on incontinence questionnaire (ICIQ), Short form: It was used to elicit the history of urinary incontinence [10]. The approval for using original ICIQ questionnaire was obtained via e-mail communication with the concerned authority for its use in this study. The ICIQ-UI Short form covers all the domain of incontinence and consists of score ranging from 0 - 21. Higher the score, greater the severity of symptoms. The provided form was translated in local language (Hindi, Punjabi) along with English version for better evaluation of urinary incontinence symptoms.

Quality of life tool: WHOQOL- Age tool was used to assess the parameters of quality of life index [11]. It is a 26-item instrument consisting of four domains: physical health (7 items), psychological health (6 items), social relationships (3 items), and environmental health (8 items); it also contains QOL and general health items. It consists of scoring that ranges from 1 to 5 on a response scale.

\section{Data management and analysis}

Data was entered into excel sheet and analysed using Statistical Package for the Social Sciences (version 22.0). Proportions, frequency, and means were estimated. Chi-square test was used to assess whether there is a significant difference in the proportions in different groups. Statistical significance was determined at the
95 percent confidence interval.

\section{Ethical approval and informed consent}

Ethical approval was obtained from the Ethical Review Committee, Fortis Hospital, Mohali, India on 6/9/2019. (ECR/28/Inst/ PB/2013/RR-19). Informed consent (in regional language) was obtained from all the participants.

\section{Results}

Of the total 1018 women, majority were multiparous in the average age group of 36 - 45 years (26.9\%), and $91.3 \%$ belonged to urban areas (deciding by their present stay at the time of study). This study covers participants majorly from Punjab (57.3\%) followed by Chandigarh (30.7\%), Haryana (6.2\%) and other states: Delhi, Himachal Pradesh, Jammu and Kashmir, Maharashtra, Uttar Pradesh (5.8\%). Nearly $74.2 \%$ of study population did not have any incontinence symptoms. About $8.1 \%$ of the respondents with UI described the frequency of their urinary leakage about once a week (mild in frequency), 8.0\% moderate (leakage of urine 2 or 3 times a week or about once a day), while $3.4 \%$ had severe frequency (leaked several times a day/all the time) during a time period of previous one year. The amount of urine leakage was reported to be small by $18.7 \%$ and moderate by $5.6 \%$ women (Table 1 ).

\begin{tabular}{|l|c|c|}
\hline Parameters & $\begin{array}{c}\text { Number } \\
\text { N = 1018 }\end{array}$ & $\begin{array}{c}\text { Percentage } \\
\text { (\%) }\end{array}$ \\
\hline Age group (years) & & \\
\hline $15-25$ & 61 & 6.0 \\
\hline $26-35$ & 239 & 23.5 \\
\hline $36-45$ & 274 & 26.9 \\
\hline $46-55$ & 229 & 22.5 \\
\hline $56-65$ & 143 & 14.0 \\
\hline $66-75$ & 54 & 5.3 \\
\hline $76-85$ & 15 & 1.5 \\
\hline$>86$ & 3 & .3 \\
\hline State & & \\
\hline Punjab & 583 & 57.3 \\
\hline Haryana & 63 & 6.2 \\
\hline Chandigarh & 313 & 30.7 \\
\hline Other states (Delhi, HP, & 59 & 5.8 \\
\hline JK, MH, UP) & & \\
\hline Area & 929 & 91.3 \\
\hline Urban & & 8.7 \\
\hline Rural & & \\
\hline & & \\
\hline & & \\
\hline
\end{tabular}

Table 1a: Background characteristics of the study participants. 
Female Urinary Incontinence - A Revisit on Prevalence of this Problem in Today's Society, which is Increasing due to Increase in Average Life Span

\begin{tabular}{|l|c|c|}
\hline $\begin{array}{l}\text { Frequency of urine leakage } \\
\text { as per history }\end{array}$ & \multicolumn{2}{|c|}{ SD = 277.3 } \\
\hline Never & 755 & 74.2 \\
\hline Once a week or less often & 82 & 8.1 \\
\hline 2-3 times/week & 81 & 8.0 \\
\hline Once a day & 55 & 5.4 \\
\hline Several times a day & 35 & 3.4 \\
\hline
\end{tabular}

Table 1b: ICIQ questionnare domains studied among participants.

\begin{tabular}{|l|l|l|}
\hline Amount of urine leaked & SD= 301.7 \\
\hline None & 764 & 75.0 \\
\hline Small amount & 190 & 18.7 \\
\hline Moderate amount & 57 & 5.6 \\
\hline Large amount & 7 & 0.7 \\
\hline
\end{tabular}

Table 1c

\begin{tabular}{|l|c|c|}
\hline Timing of leakage of urine & \multicolumn{2}{|c|}{ SD=274.9 } \\
\hline Never & 740 & 72.7 \\
\hline Before you can get to the toilet & 38 & 3.7 \\
\hline Leaks when you cough or sneeze & 67 & 6.6 \\
\hline Leaks when you are asleep & 104 & 10.2 \\
\hline $\begin{array}{l}\text { Leaks when you are physically } \\
\text { active or exercising }\end{array}$ & 17 & 1.7 \\
\hline
\end{tabular}

Table 1d

The overall prevalence of urinary incontinence in the study women was $25.8 \%$. It was significantly $(\mathrm{p}<0.05)$ higher in age groups of $76-85(46.7 \%)$ and $66-75$ years (33.6\%) as compared to other groups. About $14.8 \%$ women in the age group of $15-25$ years were also affected. It was higher in rural $(28.1 \%)$ than urban (25.6\%) population. The geographic distribution shows higher prevalence of UI in Chandigarh (31.9\%) as compared with Punjab (22.8\%) and Haryana (28.6\%) (Table 2). Among those women who had UI, $46.0 \%$ were having stress urinary incontinence and $37.1 \%$ had urge incontinence.

To evaluate overall satisfaction with life (SWL), respondents were asked "Taking all things together, how satisfied are you with your life as a whole in last two weeks time frame and their responses were ranked on a scale ranging from 1 = very dissatisfied,

\begin{tabular}{|l|c|c|c|}
\hline \multirow{2}{*}{ Parameter } & \multicolumn{2}{|c|}{ Stress urinary incontinence } & \multirow{2}{*}{ P value } \\
\cline { 2 - 3 } & Yes & No & \\
\cline { 1 - 3 } & N (\%) & N (\%) & \\
\hline Overall Prevalence & $263(25.8)$ & $755(74.2)$ & \\
\hline $15-25$ & & & 0.000 \\
\hline $26-35$ & $9(14.8)$ & $52(85.2)$ & \\
\hline $36-45$ & $35(14.6)$ & $204(85.4)$ & \\
\hline $46-55$ & $70(25.5)$ & $204(74.5)$ & \\
\hline $56-65$ & $72(31.4)$ & $157(68.6)$ & \\
\hline $66-75$ & $48(33.6)$ & $95(66.4)$ & \\
\hline $76-85$ & $21(38.9)$ & $33(61.1)$ & \\
\hline$>86$ & $7(46.7)$ & $8(53.3)$ & \\
\hline
\end{tabular}

Table 2: Age and area wise distribution of prevalence of stress urinary incontinence.

to $5=$ very satisfied. The quality of life index parameters showed there was not much difference in the quality of life between those women with SUI (9.1\%) and those without (9.5\%). ( $p=0.696)$. However, satisfaction level with respect to own ability to perform daily living activities was significantly less among women with SUI (30.8\% very satisfied) as compared with women without SUI $(40.4 \%$ very satisfied) $(p=0.022)$ (Table 3$)$.

\section{Discussion}

In our study, prevalence was $25.8 \%$, aligned with the results earlier reported in other studies of Singh., et al. [8], Prabhu and Shanbhag [12], and Sembiah., et al. [13] The two most relevant papers on the epidemiology of UI are the Epincont study $[14,15]$ and the meta-analysis by Minassian., et al. [16]; the author, using standardized definitions and questionnaires, reported a prevalence of any form of UI of $25 \%$ and $27.6 \%$ respectively. This means that if we produce well-designed studies, we can obtain highly reproducible and accurate epidemiological data. It is well demonstrated that the prevalence of UI is influenced by the age and by the gender of the considered population [17].

In our study in the younger women (18 - $35 \mathrm{yrs),} \mathrm{the} \mathrm{prevalence}$ of any incontinence was lower at (14.8\%) as compared to older women (46.7\%) as younger ones has more incidence of stress incontinence than older because of any bladder irritant, weakened pelvic floor due to child birth trauma, heavy lifting and running. 
Female Urinary Incontinence - A Revisit on Prevalence of this Problem in Today's Society, which is Increasing due to Increase in Average Life Span

\begin{tabular}{|c|c|c|c|c|}
\hline \multirow[b]{2}{*}{ Parameter } & \multicolumn{2}{|c|}{ Stress urinary incontinence } & \multirow{2}{*}{$\begin{array}{c}\text { Total } \\
\text { N = } 1018\end{array}$} & \multirow[b]{2}{*}{$P$ value } \\
\hline & $\begin{array}{c}\text { Yes } \\
N=263(\%)\end{array}$ & $\begin{array}{c}\text { No } \\
\text { N = } 755(\%)\end{array}$ & & \\
\hline Rating of Quality of life as per respondent & & & & 0.696 \\
\hline Bad & $101(38.4)$ & $6(0.8)$ & $107(10.5)$ & \\
\hline Neither good or bad & $44(16.7)$ & $72(9.5)$ & $116(11.4)$ & \\
\hline Good & $50(19.0)$ & $396(52.5)$ & $446(43.8)$ & \\
\hline Very good & $68(25.9)$ & $281(37.2)$ & $349(34.2)$ & \\
\hline $\begin{array}{l}\text { Satisfaction level with respect to hearing, vision or other } \\
\text { senses overall }\end{array}$ & & & & 0.141 \\
\hline Dissatisfied & $4(1.5)$ & $4(0.5)$ & $8(0.8)$ & \\
\hline Neither satisfied nor dissatisfied & $18(6.8)$ & $67(8.9)$ & $85(8.3)$ & \\
\hline Satisfied & $140(53.2)$ & $361(47.8)$ & $501(49.2)$ & \\
\hline Very satisfied & $101(38.4)$ & $323(42.8)$ & $424(41.7)$ & \\
\hline Satisfaction level with respect to own health & & & & 0.217 \\
\hline Dissatisfied & $5(1.9)$ & $6(0.8)$ & $11(1.1)$ & \\
\hline Neither & $33(12.5)$ & $75(9.9)$ & $108(10.6)$ & \\
\hline Satisfied & $133(50.6)$ & $377(49.9)$ & $510(50.1)$ & \\
\hline Very satisfied & $92(35.0)$ & $297(39.3)$ & $389(38.2)$ & \\
\hline Satisfaction level with respect to own self & & & & 0.446 \\
\hline Dissatisfied & $2(0.8)$ & $1(0.1)$ & $3(0.3)$ & \\
\hline Neither & $24(9.1)$ & $71(9.4)$ & $95(9.3)$ & \\
\hline Satisfied & $135(51.3)$ & $394(52.2)$ & $529(52.0)$ & \\
\hline Very satisfied & $102(38.8)$ & $289(38.3)$ & $391(38.4)$ & \\
\hline $\begin{array}{l}\text { Satisfaction level with respect to own ability to perform } \\
\text { daily living activities }\end{array}$ & & & & 0.022 \\
\hline Dissatisfied & $0(0.0)$ & $4(0.5)$ & $4(0.4)$ & \\
\hline Neither satisfied nor dissatisfied & $24(9.1)$ & $65(8.6)$ & $89(8.7)$ & \\
\hline Satisfied & $158(60.1)$ & $381(50.5)$ & $539(52.9)$ & \\
\hline Very satisfied & $81(30.8)$ & $305(40.4)$ & $386(37.9)$ & \\
\hline Satisfaction level with respect to personal relationships & & & & 0.958 \\
\hline Dissatisfied & $4(1.5)$ & $10(1.3)$ & $14(1.4)$ & \\
\hline Neither & $26(9.9)$ & $70(9.3)$ & $96(9.4)$ & \\
\hline Satisfied & $133(50.6)$ & $375(49.7)$ & $508(49.9)$ & \\
\hline Very satisfied & $100(38.0)$ & $300(39.7)$ & $400(39.3)$ & \\
\hline $\begin{array}{l}\text { Satisfaction level with respect to the conditions of your } \\
\text { living place }\end{array}$ & & & & 0.967 \\
\hline Dissatisfied & $2(0.8)$ & $6(0.8)$ & $8(0.8)$ & \\
\hline Neither satisfied nor dissatisfied & $19(7.2)$ & $56(7.4)$ & $75(7.4)$ & \\
\hline Satisfied & $111(42.2)$ & $305(40.4)$ & $416(40.9)$ & \\
\hline Very satisfied & $131(49.8)$ & $388(51.4)$ & $519(51.0)$ & \\
\hline Satisfaction level with respect to the way you use your time & & & & 0.132 \\
\hline
\end{tabular}


Female Urinary Incontinence - A Revisit on Prevalence of this Problem in Today's Society, which is Increasing due to Increase in Average Life Span

\begin{tabular}{|c|c|c|c|c|}
\hline Dissatisfied & $0(0.0)$ & $1(0.1)$ & $1(0.1)$ & \\
\hline Neither & $17(6.5)$ & $26(3.4)$ & $43(4.2)$ & \\
\hline Satisfied & $115(43.7)$ & $315(41.7)$ & $430(42.2)$ & \\
\hline Very satisfied & $131(49.8)$ & $413(54.7)$ & $544(53.4)$ & \\
\hline $\begin{array}{l}\text { Satisfaction level with respect to intimate relationships in } \\
\text { the life }\end{array}$ & & & & 0.713 \\
\hline Very dissatisfied & $10(3.8)$ & $5(0.7)$ & $15(1.4)$ & \\
\hline Dissatisfied & $68(25.9)$ & $4(0.5)$ & $72(7.0)$ & \\
\hline Neither & $15(5.7)$ & $45(6.0)$ & $60(5.9)$ & \\
\hline Satisfied & $119(45.2)$ & $345(45.7)$ & $464(45.6)$ & \\
\hline Very satisfied & $51(19.3)$ & $356(47.2)$ & 407 (39.9) & \\
\hline
\end{tabular}

Table 3: Prevalence of stress urinary incontinence and its association with the quality of life.

Similar result was shown in a meta-analysis of 48 studies, by Hampel and colleagues estimating the prevalence of urinary incontinence to be $16 \%$ for women younger than 30 years and $29 \%$ for women aged 30 to 60 years [18]. This is understandable as number of pregnancies, child birth, vaginal wear and tear and age related atrophic changes are less in younger age group [18].

Among the women who reported urinary incontinence, also the type of incontinence differed by age group. The prevalence of urge and mixed incontinence was more in older age group (urge incontinence was $70 \%$ among women $>60$ years vs. $45 \%$ among women $\leq 60$ years) [19] because of multiple child births, overactive bladder, nerve damage due to spinal injury, comorbidities such as diabetes.

Other investigators also found SUI to be more common than urge urinary incontinence, with $78 \%$ of women having SUI versus $51 \%$ with urge urinary incontinence [20]. In our study similar results were seen $(46.0 \%$ of women having stress urinary incontinence versus $37.1 \%$ with urge incontinence).

\section{Conclusion}

Urinary incontinence is a common problem, about 1 in every 4 women suffer from urinary incontinence. Health care professionals should take this problem seriously and consider the psychological effects of this disease as it can affect social, mental and physical well being of the women population. Preventive exercises like Kegel exercise are not very effective but nowadays non invasive treatment like laser, HIFEM, radiofrequency, PRP and HIFU are more lucrative options because of better patient compliance and lesser side effects. The clinicians should look into advanced and non-inva- sive treatment for urinary incontinence. Also we should be aware of this condition because only by knowing the true prevalence of a disease we can make a real prevention and cure of it.

\section{Acknowledgement}

We would like to thank all the people who participated in this study and made it possible. Also we would like to thank Ms Aanchal and Ms Priya for their contribution in giving shape to this study.

\section{Bibliography}

1. Jindal P., et al. "Non Surgical Management of Stress Urinary Incontinence (SUI)". Acta Scientific Women's Health 2 (2020): 51-54.

2. Irwin DE., et al. "Population-based survey of urinary incontinence, overactive bladder, and other lower urinary tract symptoms in five countries: results of the EPIC study". European Urology 50.6 (2006): 1306-1314; discussion 1314-1315.

3. Thom D. "Variation in estimates of urinary incontinence prevalence in the community: effects of differences in definition, population characteristics, and study type". Journal of the American Geriatrics Society 46.4 (2006): 473-480.

4. Melville JL., et al. "Women's perceptions about the etiology of urinary incontinence". Journal of Womens Health (Larchmt) 17.7 (2008): 1093-1098.

5. Haylen BT., et al. "An International Urogynecological Association (IUGA)/International Continence Society (ICS) joint re- 
port on the terminology for female pelvic floor dysfunction". International Urogynecology Journal 21.1 (2010): 5-26.

6. Cundiff GW. "The pathophysiology of stress urinary incontinence: a historical perspective". Review on Urology 6 (2004): S10-S18.

7. Guin Gita., et al. "Prevalence of stress urinary incontinence and its associated risk factors amongst females attending tertiary referral centre". International Journal of Reproduction, Contraception, Obstetrics and Gynecology 7.6 (2018): 2115-2119.

8. Aoki Y., et al. "Urinary incontinence in women". Nature Reviews Disease Primers 3 (2017): 17042.

9. Singh U., et al. "Prevalence and risk factors of urinary incontinence in Indian women: A hospital-based survey". Indian Journal of Urology 29 (2013): 31-36.

10. Timmermans L., et al. "Validation of use of the International Consultation on Incontinence Questionnaire-Urinary Incontinence-Short Form (ICIQ-UI-SF) for impairment rating: a transversal retrospective study of 120 patients". Neurourology and Urodynamics 32.7 (2013): 974-979.

11. Caballero FF., et al. "Validation of an instrument to evaluate quality of life in the aging population: WHOQOL-AGE". Health Qual Life Outcomes 11 (2013): 177.

12. Prabhu SA and Shanbhag SS. "Prevalence and risk factors of urinary incontinence in womenresiding in a tribal area in Maharashtra, India". Journal of Research in Health Sciences 13 (2013): 125-130.

13. Biswas B., et al. "Urinary Incontinence, Its Risk Factors, and Quality of Life: A Study among Women Aged 50 Years and above in a Rural Health Facility of West Bengal". Journal of Midlife Health 8.3 (2017): 130-136.

14. Hannestad YS., et al. "Epidemiology of Incontinence in the County of Nord-Trøndelag. A community-based epidemiological survey of female urinary incontinence: the Norwegian EPINCONT study. Epidemiology of Incontinence in the County of Nord-Trøndelag". Journal of Clinical Epidemiology 53.11 (2000): 1150-1157.

15. Ebbesen MH., et al. "Prevalence, incidence and remission of urinary incontinence in women: longitudinal data from the Norwegian HUNT study (EPINCONT)". BMC Urology 13 (2013): 27.

16. Minassian VA., et al. "Urinary incontinence as a worldwide problem". International Journal of Gynecology and Obstetrics 82.3 (2003): 327-338.

17. Serati $M$ and Ghezzi $F$. The epidemiology of urinary incontinence: a case still open". Annals of Translational Medicine's 4.6 (2016): 123.

18. Hampel C., et al. "Definition of overactive bladder and epidemiology of urinary incontinence”. Urology 50 (1997): 4-14.

19. Glazener CM., et al. "New postnatal urinary incontinence: obstetric and other risk factors in primiparae". BJOG 113.2 (2006): 208-217.

20. Lordelo P., et al. "New concept for treating female stress urinary incontinence with radiofrequency". International Brazilian Journal of Urology 43.5 (2017): 896-902.

Volume 3 Issue 9 September 2021

(C) All rights are reserved by Jindal Preeti., et al. 